\title{
As contribuições do tradutor na área científica: uma análise da tradução do SWAL-QOL para a língua portuguesa do Brasil
}

Leila Maria Gumushian Felipini, Emanoel Henrique Alves e Luan Ribeiro Dias*

\section{Introdução}

A maioria dos instrumentos de avaliação na área da saúde foi desenvolvida em língua inglesa e tem como objetivo a aplicação em pacientes falantes desse idioma. No Brasil, há uma grande escassez de instrumentos de avaliação na área da saúde que tenham sido devidamente traduzidos, adaptados culturalmente e validados para a nossa realidade. Tal situação é descrita no artigo Instrumentos de Avaliação Estrangeiros no Contexto da Saúde Brasileira: processo de tradução, adaptação cultural e validação (Carmo et al., 2012).

Essa situação é resultado de uma prática não padronizada que está sendo desenvolvida nos processos de tradução e adaptação cultural por profissionais da área da saúde. Apesar de haver autores que propõem diretrizes para esse tipo de processo, a maioria dos processos de tradução na área da saúde não conta, por exemplo, com a participação do tradutor, profissional que possui conhecimentos especializados que o preparam para lidar com as especificidades tanto do idioma de partida quanto do idioma de chegada. Há palavras que são específicas, pois refletem aspectos culturais presentes

\footnotetext{
* Leila Maria Gumushian Felipini é professora do curso de graduação Letras-Tradutor da Universidade do Sagrado Coração. Emanoel Henrique Alves é Professor Titular de Educação Básica em Língua Inglesa na Secretaria de Estado de Educação de São Paulo. Luan Ribeiro Dias é aluno do Ensino Médio participante do PIBIC-EM na USC, bolsista do CNPQ.
} 
no contexto apenas de determinado povo e que acabam por dificultar o processo tradutório, exigindo que o tradutor faça uso de estratégias tradutórias que são parte da sua formação. Outra discrepância é verificada no número de participantes que cumprem a função de "tradutores" e "retrotradutores" ${ }^{1}$, assim como no número de etapas seguidas nesses processos.

Desenvolvido como pesquisa de iniciação científica na Universidade do Sagrado Coração com a participação de um aluno de graduação e um aluno do ensino médio, este trabalho buscou demonstrar a relevância da participação do profissional tradutor em processos tradutórios envolvendo instrumentos de avaliação na área da saúde. Para isso, realizamos uma análise comparativa entre as versões original e traduzida de um questionário de avaliação de qualidade de vida em disfagia, o SWAL-QOL. Essa análise comparativa foi realizada com base em diretrizes para a tradução na área da saúde propostas por Beaton et al. (2000), além de conceitos da teoria da tradução.

Com isso, acreditamos poder contribuir com a teoria da tradução fornecendo material de leitura para alunos de tradução e tradutores iniciantes na área da saúde, além de esclarecer para os profissionais da saúde a importância de se trabalhar com profissionais tradutores em suas pesquisas.

\section{Tradução}

A partir das características específicas das culturas envolvidas e das instruções da tarefa de tradução, o tradutor é quem define uma estratégia de trabalho que, ao mesmo tempo, "(1) preserve a referência à instância que transfere o saber específico e (2) possa ser eficaz na cultura para a qual o texto é transportado" (Azenha Junior, 1999, p. 12).

O ponto principal da abordagem funcional de Nord é o ato tradutório como uma comunicação intercultural e o modelo preocupa-se com o ambiente cultural (confronto entre duas culturas), incluindo a linguagem, a comunicação e o tradutor, intermediador deste processo. A autora define o tradutor:

\footnotetext{
${ }^{1} \mathrm{O}$ retradutor utiliza a tradução, ser ter acesso ao documento que a originou, para fazer uma nova tradução de volta ao documento de origem.
} 


\begin{abstract}
O tradutor não é o emissor da mensagem do texto de origem, mas sim um produtor do texto na cultura alvo, que adota a intenção de alguém a fim de produzir um instrumento de comunicacão para a cultura alvo, ou um documento da cultura alvo. (Nord, 2005, p.13) ${ }^{2}$
\end{abstract}

O tradutor deve ser conhecedor da cultura de origem para que o texto seja passado para a cultura alvo de forma clara e perfeitamente compreensível. Portanto, “o tradutor como receptor é bi-cultural, o que significa que ele tem um domínio perfeito tanto da cultura de origem quanto da cultura alvo (...)" (Nord, 2005, p.12).

De acordo com Nord (2005), a recepção do texto traduzido depende das expectativas individuais do receptor. Tais expectativas são determinadas pela situação na qual o receptor lê o texto, bem como por toda sua bagagem de conhecimento prévio, seu conhecimento de mundo e suas necessidades comunicativas.

Nord (ibidem) afirma que por ter crescido em outra cultura, o receptor do texto traduzido possui um conhecimento de mundo, um modo de vida, uma perspectiva diferente sobre as coisas e, também, uma "experiência textual" diferente que influenciam a leitura do texto traduzido. Para lidar com essas diferenças culturais, há uma modalidade da tradução denominada adaptação, a qual denota uma assimilação cultural. De acordo com Aubert (1998), nessa modalidade, a solução tradutória adotada para o segmento textual dado estabelece uma equivalência parcial de sentido, tida por suficiente para o ato tradutório em questão.

Para que esse processo tradutório seja adequado, é necessário que o profissional tradutor possua alguns conhecimentos, estratégias e habilidades. Segundo Alves, Magalhães \& Pagano (2000), a competência tradutória engloba todos os conhecimentos, habilidades e estratégias que o tradutor bem-sucedido possui e que levam ao exercício adequado da tarefa tradutória. A competência tradutória é considerada um conhecimento especializado que se desenvolve por meio do estudo e da prática.

\footnotetext{
${ }^{2}$ Tradução minha para: "The translator is not the sender of the ST message but a text-producer in the target culture who adopts somebody else's intention in order to produce a communicative instrument for the target culture, or a target-culture document."
} 
Considerando as características do processo tradutório descritas acima, há a necessidade de se seguirem diretrizes específicas a fim de se controlar o produto final desse processo, o texto traduzido.

\section{Diretrizes para a tradução na área da saúde}

Guillemin et al. (1993) afirmam que a grande maioria dos instrumentos de avaliação é desenvolvida na língua inglesa e que sem dúvida há necessidade de se desenvolverem instrumentos a serem utilizados em países onde o idioma é outro, uma vez que grupos culturais se expressam de maneira diferente sobre doenças e quanto ao uso de sistemas variados de cuidado com a saúde. Além disso, a percepção quanto à qualidade de vida e os modos em que os problemas de saúde são expressos também variam de cultura para cultura. É relatado ainda que, na maioria das vezes, os instrumentos precisam ser adaptados para serem usados em um país com idioma e cultura diferentes. De acordo com os autores, o nível de adaptação necessária varia de acordo com a similaridade ou diferença entre as estruturas de língua e de cultura.

Guillemin et al. (ibidem) explicam que a adaptação cultural é composta pela tradução e pela adaptação, ou seja, uma combinação de tradução literal de palavras e sentenças de um idioma para outro e uma adaptação com relação ao idioma, ao contexto cultural e ao estilo de vida. Os autores recomendam diretrizes para a preservação da equivalência na adaptação transcultural em medidas de qualidade de vida relacionadas à saúde. As diretrizes são compostas por cinco etapas: (1) tradução, (2) retrotradução, (3) comitê de revisão, (4) pré-teste e (5) possível adaptação dos pesos das pontuações para o contexto cultural.

A experiência adicional com o processo de adaptação transcultural de instrumentos gerais ou específicos para algumas doenças, além de estratégias alternativas propostas por grupos de pesquisadores, levou a um refinamento dessa metodologia proposta por Guillemin et al. em 1993 (Beaton et al., 2000). A nova proposta foi elaborada com base em uma revisão do processo de adaptação transcultural com base nas literaturas médica, da psicologia e da sociologia. As diretrizes reformuladas propostas por Beaton et 
al. (ibidem) apresentam cinco etapas: (1) traduções, (2) síntese das traduções, (3) retrotraduções, (4) comitê de peritos e (5) teste da versão prévia.

De acordo com as diretrizes de 2000, há algumas sugestões a serem seguidas para se assegurar a compreensão total da tradução. Uma delas é o uso de uma linguagem que possa ser compreendida por indivíduos de dez a 12 anos de idade. Entre as recomendações estão também a participação de profissionais qualificados no processo de tradução do original, o uso de uma linguagem o mais simples possível, a substituição da voz passiva pela voz ativa, a repetição dos substantivos no lugar de pronomes e o uso de termos específicos em vez de termos mais gerais. É sugerido que os autores (tradutores) evitem o uso de metáforas e coloquialismos, o modo subjetivo, advérbios e preposições se referindo a onde e quando, formas possessivas, palavras vagas, sentenças com dois verbos diferentes sugerindo ações diferentes.

As diretrizes propostas tanto por Guillemin et al. (1993) quanto por Beaton et al. (2000) incluem orientações para se atingir uma equivalência semântica, idiomática, experiencial e conceitual entre o original e sua tradução. Beaton et al. (ibidem) afirmam que a revisão feita nas literaturas médica, da psicologia e da sociologia levou a um modelo de processo de adaptação transcultural que maximiza essas equivalências. A equivalência semântica se refere à equivalência no significado das palavras, uma vez que algumas palavras podem apresentar significados um pouco diferentes dependendo do contexto. Rónai (1981, p. 17) afirma que "as palavras não possuem sentido isoladamente, mas dentro de um contexto, e por estarem dentro desse contexto".

De acordo com Beaton et al. (2000), a equivalência semântica busca equacionar as dificuldades causadas por significados múltiplos, além de problemas gramaticais que podem surgir no processo de tradução. A equivalência idiomática se refere às expressões idiomáticas e coloquialismos. Nesses casos, expressões equivalentes devem ser usadas ou alguns itens devem ser substituídos. Para Guillemin et al. (1993), é mais provável que essas adequações sejam necessárias nas dimensões social e emocional. A equivalência experimental depende de as situações evocadas no original se encaixarem no contexto da cultura-alvo. Beaton et al. (2000) definem esse tipo de equivalência como a tradução dos hábitos da vida diária de uma determinada cultura 
e explicam que uma tarefa específica pode não ser experimentada por determinado povo, como o uso do garfo na alimentação, que não é comum a todas as culturas. Já a equivalência conceitual se refere à validade do conceito explorado e às experiências vividas pelas pessoas na cultura-alvo, uma vez que algumas palavras podem apresentar equivalência semântica, mas não conceitual. Ou seja, o conceito de uma palavra varia de cultura para cultura. Beaton et al. (ibidem) citam como exemplo o conceito da palavra "família", cujo significado pode variar entre família nuclear ou extensa dependendo da cultura.

\section{O questionário SWAL-QOL}

O questionário original, chamado Quality of Life in Swallowing Disorders (SWAL-QOL), foi elaborado nos Estados Unidos por McHorney et al. (2000). No Brasil, foi traduzido e adaptado culturalmente por Montoni \& Alves (2006) no programa de pós-graduação Lato Sensu e validado por Portas (2009) no programa de mestrado em medicina, ambos da Fundação Antônio Prudente. O processo de tradução e adaptação cultural envolveu testes em campo contando com 22 pacientes disfágicos tratados por câncer de cabeça e pescoço.

O questionário original apresenta 44 questões que avaliam dez domínios: seleção de alimentos, deglutição como um fardo, saúde mental, função social, medo de se alimentar, duração da alimentação, desejo de se alimentar, comunicação, sono e fadiga (McHorney et al., 2002). O questionário traduzido também é constituído de 44 questões, mas estas por sua vez são divididas em 11 domínios (Montoni \& Alves, 2006) e mantêm o domínio frequência de sintomas, excluído na validação do questionário original. No questionário, o paciente responde sobre a frequência com que ocorrem as situações expostas em cada domínio, e os itens de resposta são: sempre, muitas vezes, algumas vezes, um pouco ou nunca.

O escore varia de 0 a 100, e quanto mais baixo, pior a qualidade de vida relacionada à deglutição. O escore final é resultante da soma dos valores obtidos no escore em cada domínio. O objetivo desse instrumento é contribuir durante o processo terapêutico, monitorando a eficácia da reabilitação na perspectiva do paciente. Ele é sensível para diferenciar a deglutição de 
indivíduos normais de pacientes disfágicos por diferentes etiologias e para diferenciar o grau das alterações da deglutição.

A análise comparativa entre as duas versões desse questionário foi realizada tendo como parâmetros as diretrizes propostas por Beaton et al. (2000), além de teorias da tradução.

\section{Análise}

Para iniciarmos a análise, descreveremos as alterações feitas na tradução do questionário em relação à sua estrutura, como a divisão de um item em dois ou a omissão de partes do conteúdo do original.

No questionário original, a questão 9 é apresentada da seguinte forma:

9. In the last month, how often have you experienced each of the following physical symptoms?

\begin{tabular}{lrrrrrr}
\hline & $\begin{array}{c}\text { All of the } \\
\text { time }\end{array}$ & $\begin{array}{c}\text { Most of } \\
\text { the time }\end{array}$ & $\begin{array}{c}\text { Some of } \\
\text { the time }\end{array}$ & $\begin{array}{c}\text { A little of } \\
\text { the time }\end{array}$ & $\begin{array}{c}\text { None of the } \\
\text { time }\end{array}$ \\
\hline Feel weak? & 1 & 2 & 3 & 4 & 5 \\
\hline Have trouble falling asleep? & 1 & 2 & 3 & 4 & 5 \\
\hline Feel tired? & 1 & 2 & 3 & 4 & 5 \\
\hline Have trouble staying asleep? & 1 & 2 & 3 & 4 & 5 \\
Feel exhausted? & 1 & 2 & 3 & 4 & 5 \\
\hline
\end{tabular}

Fonte: SWAL-QOL

Tabela 1 - Questão 9 e seus itens de resposta (original)

Já na tradução, o conteúdo desse item é apresentado dividido em duas questões, a 9 e a 10, ou seja, o questionário passa a apresentar um item a mais que o original: 


\begin{tabular}{|lccccc|}
\hline 9. No último mês, quantas vezes você sentiu algum destes sintomas físicos? \\
\hline & Sempre & $\begin{array}{c}\text { Muitas } \\
\text { vezes }\end{array}$ & $\begin{array}{c}\text { Algumas } \\
\text { vezes }\end{array}$ & Um pouco & Nunca \\
\hline Tem problemas para dormir a noite toda? & 1 & 2 & 3 & 4 & 5 \\
Tem problema para dormir? & 1 & 2 & 3 & 4 & 5 \\
\hline
\end{tabular}

Fonte: SWAL-QOL traduzido e adaptado para a língua portuguesa do Brasil

Tabela 2 - Questão 9 e seus itens de resposta (tradução)

10. No último mês, quantas vezes você sentiu algum desses sintomas físicos?

\begin{tabular}{|lrrrrc|}
\hline & Sempre & $\begin{array}{l}\text { Muitas } \\
\text { vezes }\end{array}$ & $\begin{array}{l}\text { Algumas } \\
\text { vezes }\end{array}$ & Um pouco & Nunca \\
\hline Sente-se cansado? & 1 & 2 & 3 & 4 & 5 \\
Sente-se fraco? & 1 & 2 & 3 & 4 & 5 \\
Sente-se exausto? & 1 & 2 & 3 & 4 & 5 \\
\hline
\end{tabular}

Fonte: SWAL-QOL traduzido e adaptado para a língua portuguesa do Brasil

Tabela 3 - Questão 10 e seus itens de resposta (tradução)

A leitura das instruções referentes ao escore do protocolo indica que essa divisão foi proposta considerando que os itens de resposta da questão 9 do original contemplavam dois domínios, sono e fadiga, dos 10 que constituem o questionário original: seleção de alimentos, deglutição como um fardo, saúde mental, função social, medo de se alimentar, duração da alimentação, desejo de se alimentar, comunicação, sono e fadiga (McHorney et al., 2002). Dessa forma, na tradução, os itens pertencentes ao domínio sono permaneceram na questão 9, e os itens referentes ao domínio fadiga foram colocados na questão 10. Tal alteração parece buscar facilitar o cálculo do escore de cada paciente, o qual é estabelecido pela soma do escore de todas as questões dentro do domínio e sua posterior divisão pelo número de questões do domínio, conforme exemplo a seguir: 
9. No último mês, quantas vezes você sentiu algum desses sintomas físicos?

\begin{tabular}{|lccccc|}
\hline & Sempre & $\begin{array}{c}\text { Muitas } \\
\text { vezes }\end{array}$ & $\begin{array}{c}\text { Algumas } \\
\text { vezes }\end{array}$ & Um pouco & Nunca \\
\hline Tem problemas para dormir a noite toda? & 0 & 25 & 50 & 75 & 100 \\
Tem problema para dormir? & 0 & 25 & 50 & 75 & 100 \\
\hline
\end{tabular}

Fonte: SWAL-QOL traduzido e adaptado para a língua portuguesa do Brasil

Tabela 4 - Escore da questão 9 e seus itens de resposta (tradução)

Escore domínio deglutição como um fardo $=\underline{0+50}=\mathbf{2 5}$

$$
2 \rightarrow \text { (número de questões) }
$$

Outra alteração estrutural verificada na tradução foi a ausência do exemplo que o original traz logo no início do questionário:

Here's an example of how the questions in the survey will look.

\begin{tabular}{|l|ccccc|}
\hline 9. In the last month, how often have you experienced each of symptoms below? \\
\hline $\begin{array}{c}\text { All of the } \\
\text { time }\end{array}$ & $\begin{array}{c}\text { Most of } \\
\text { the time }\end{array}$ & $\begin{array}{c}\text { Some of } \\
\text { the time }\end{array}$ & $\begin{array}{c}\text { A little of } \\
\text { the time }\end{array}$ & $\begin{array}{c}\text { None of } \\
\text { the time }\end{array}$ \\
\hline Feel weak? & 1 & 2 & 3 & 4 & 5 \\
\hline
\end{tabular}

Fonte: SWAL-QOL

Tabela 5 - Exemplo inicial para o paciente (original)

Na tradução consta apenas a orientação entre parênteses "circular um número em cada linha" antes do item 1, o que, ao contrário da primeira alteração descrita, parece dificultar a aplicação do questionário, uma vez que o recurso visual é considerado como um apoio para a compreensão da tarefa a ser realizada. Outras omissões, sejam elas de frases, recursos como negrito ou itálico ou exemplos de comida, também foram verificadas no texto, e todas parecem prejudicar a compreensão do questionário. Isso pode até mesmo fazer com que o leitor responda algo que ele não sente ou sofre devido aos seus problemas de deglutição. 
Alguns casos de omissão encontrados no questionário:

1. Below are some general statements that people with swallowing prob$\underline{\text { lems }}$ might mention. In the last month, how true have the following statements been for you?

Fonte: Elaborado pelo autor.

Tabela 6 - Questão 1 (original)

Comparando o original à tradução, notamos que recursos como o negrito, itálico e sublinhado, que podem ser utilizados para destacar determinado conteúdo do texto, foram apagados na tradução (Normas..., [2015?]):

1. Abaixo estão algumas questões gerais que podem ser mencionadas pelas pessoas com distúrbios de deglutição. No último mês, o quanto as questões a seguir têm sido verdadeiras para você?

Tabela 7 - Questão 1 (tradução)

Dessa forma, consideramos que o ideal seria a manutenção de tais recursos, uma vez que foram utilizados no original para destacarem o conteúdo, chamando atenção do leitor para determinadas palavras ou expressões.

Outro caso encontrado foi a presença de exemplos dados no questionário original $(\mathrm{O})$ que não constam da tradução $(\mathrm{T})$, como na alternativa $\mathrm{C}$ da questão 11 do original, na qual os tipos de comida "pudding or pureed food" foram omitidos:

\begin{tabular}{|c|l|}
\hline O & $\begin{array}{l}\text { C - Circle this one if you are eating food that is put through a } \\
\text { blender or food processor or anything that is like pudding or pu- } \\
\text { reed foods. }\end{array}$ \\
\hline
\end{tabular}




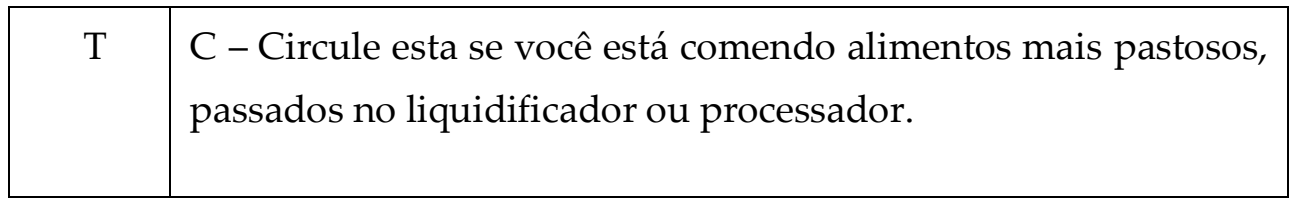

Fonte: Elaborado pelo autor.

Tabela 8 - Item de resposta da questão 11 (original)

Vemos que na tradução ocorreu a omissão dos exemplos de alimentos pastosos que constavam no original (em português, o pudim e o purê). Essas omissões não deveriam ocorrer, pois os exemplos são de muita importância para a compreensão do item pelo paciente. É por meio dos exemplos que ele poderia ter uma base de qual seria a resposta mais apropriada. Considerando que a equivalência experimental (Beaton et al., 2000), a qual depende das situações evocadas no original se encaixarem no contexto da cultura-alvo, é uma das equivalências a serem mantidas para que a tradução seja adequada, podemos afirmar que a omissão dos exemplos prejudica a equivalência entre o questionário original e sua tradução, comprometendo a resposta do paciente.

Propomos, então, a seguinte sugestão (S) no texto traduzido:

\begin{tabular}{|c|l|}
\hline S & $\begin{array}{l}\text { C-Circule esta letra se você costuma comer alimentos mais pas- } \\
\text { tosos, batidos no liquidificador ou passados no processador de } \\
\text { alimentos, como alimentos com a consistência de pudim ou } \\
\text { purê. }\end{array}$ \\
\hline
\end{tabular}

Fonte: Elaborado pelo autor.

Tabela 9 - Item de resposta da questão 12 (tradução)

Além de mantermos os exemplos "como alimentos com a consistência de pudim ou purê", contemplando assim a equivalência experimental, também propomos a adição das palavras "letra" e "batidos" a fim de utilizar uma linguagem mais simples e facilitar a leitura e a compreensão do paciente, conforme recomendado por Guillemin et al. (1993) e Beaton et al. (2000). 
Outra alteração proposta foi a troca do tempo verbal utilizado na tradução: optamos pelo uso da locução verbal "costuma comer" para indicar que a questão se refere aos hábitos do paciente.

Verificamos também a omissão na tradução do item 6 :

\begin{tabular}{|c|l|}
\hline $\mathrm{O}$ & $\begin{array}{l}\text { 6. Below are some concerns that people with swallowing prob- } \\
\text { lems sometimes mention. In the last month, how often have } \\
\text { you experienced each feeling? }\end{array}$ \\
\hline $\mathrm{T}$ & $\begin{array}{l}\text { 6. Abaixo estão algumas preocupações que as pessoas com pro- } \\
\text { blema de deglutição às vezes mencionam. No último mês, qual } \\
\text { a periodicidade que apresentou cada uma dessas preocupa- } \\
\text { ções? }\end{array}$ \\
\hline
\end{tabular}

Fonte: Elaborado pelo autor.

Tabela 10 - Questão 6

Verificamos na primeira parte desse item que a tradução soa confusa por ter sido feita literalmente. A tradução literal, de acordo com Barbosa (2004), é definida como "aquela em que se mantém uma fidelidade semântica estrita, adequando porém a morfossintaxe às normas gramaticais da LT". Dessa forma, a fim de tornarmos o texto mais claro, sugerimos a troca do verbo "mencionam" pelo adjetivo no particípio passado "mencionadas", fazendo uso de um procedimento da tradução denominado "transposição facultativa". De acordo com Barbosa (ibidem), a transposição ocorre quando um significado expresso no texto original por um significante de uma categoria gramatical passa a ser expresso no texto traduzido por um significante de outra categoria gramatical, sem que seja alterada a mensagem original. Além disso, sugerimos a troca da preposição "com" pelo verbo "apresentam": 


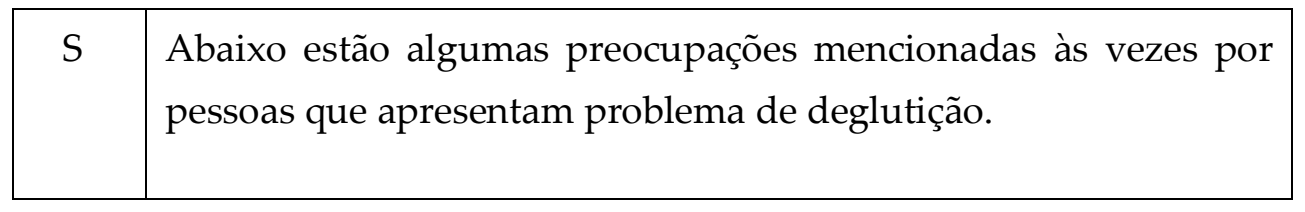

Fonte: Elaborado pelo autor.

Tabela 11 - Questão 6

Verificamos ainda na segunda parte desse item a omissão do pronome pessoal do caso reto "você" na tradução e o uso da palavra "periodicidade". Essas escolhas não se adequam às diretrizes propostas por Guillemin et al. (1993) e Beaton et al. (2000), pois ambos pedem o uso de uma linguagem o mais simples possível. Sugerimos a manutenção do pronome pessoal do caso reto "você" e a substituição da palavra "periodicidade" por "com que frequência". O substantivo "frequência" é um dos sinônimos de periodicidade, portanto a troca não altera o significado do termo original, apenas facilita a leitura por ser um termo mais coloquial. (Sinônimos.., c.2011-2015).

\begin{tabular}{|c|l|}
\hline $\mathrm{O}$ & $\begin{array}{l}\text { In the last month, how often have you experienced each feel- } \\
\text { ing? }\end{array}$ \\
\hline $\mathrm{T}$ & $\begin{array}{l}\text { No último mês, qual a periodicidade que apresentou cada uma } \\
\text { dessas preocupações? }\end{array}$ \\
\hline $\mathrm{S}$ & $\begin{array}{l}\text { No último mês, com que frequência você apresentou cada uma } \\
\text { dessas preocupaços? }\end{array}$ \\
\hline
\end{tabular}

Fonte: Elaborado pelo autor.

Tabela 12 - Questão 6

$\mathrm{Na}$ análise do questionário, notamos logo no seu início o uso de outro termo que pode ser considerado complexo para a compreensão do paciente, "NOTA". Vejamos a seguir: 


\begin{tabular}{|c|l|}
\hline $\mathrm{O}$ & $\begin{array}{l}\text { IMPORTANT NOTE: We understand that you may have a number of physical } \\
\text { problems. }\end{array}$ \\
\hline $\mathrm{T}$ & NOTA IMPORTANTE: Entendemos que você pode ter vários problemas físicos. \\
\hline
\end{tabular}

Fonte: SWAL-QOL

Tabela 13 - Orientações iniciais

"Note" significa "something that you write down to remind you of something", em tradução livre, "algo que se escreve para se lembrar de alguma coisa" (note, [2015?]). Em português, o significado de "nota" é marca, curta indicação para lembrar alguma coisa (nota, c2009-2015). Apesar de ser um equivalente apropriado semanticamente, sugerimos o uso do substantivo "observação", sinônimo de nota e termo de mais fácil compreensão (Sinônimos..., c2011-2015):

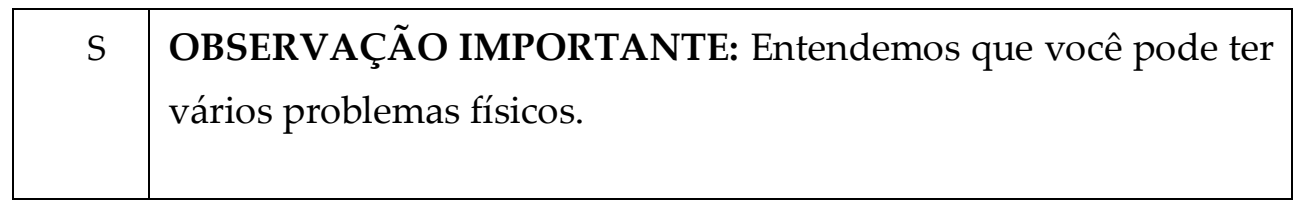

Fonte: Elaborado pelo autor.

Tabela 14 - Sugestão

Além das inadequações citadas acima, como o uso de palavras muito complexas e a omissão de termos essenciais, observamos também inadequações quanto à escolha dos equivalentes. Foram vários os casos de inadequações de escolha do equivalente encontrados na tradução do questionário, como a tradução de "don't mind" no item 2. Nesse caso, por ser muito informal, a tradução escolhida pode prejudicar a compreensão do sentido do item.

Vejamos a seguir: 


\begin{tabular}{|c|l|}
\hline $\mathrm{O}$ & Most days, I don't care if I eat or not. \\
\hline $\mathrm{T}$ & Na maioria dos dias, sinto que tanto faz se como ou não. \\
\hline
\end{tabular}

Fonte: Elaborado pelo autor.

Tabela 15 - Item de resposta da questão 2

O verbo "care" tem como definição "to think that something is important, so that you are interested in it, worried about it etc", em português, "achar que algo é importante, por isso você se interessa e se preocupa a respeito" (note, [2015?]). No questionário, a expressão foi traduzida como "tanto faz", que, apesar de contemplar em parte o sentido correto, é muito informal para ser usado neste contexto. Sugerimos então que a tradução mais apropriada para "don't care" seria "não me importo" se como ou não. Outra sugestão seria a omissão do trecho "sinto que", adicionado na tradução do questionário sem necessidade.

Analisamos também os casos de inadequação quanto à padronização encontrados no questionário.

Vejamos a seguir um desses casos que foi selecionado nos itens de resposta da questão 3:

\begin{tabular}{|l|l|}
\hline \multicolumn{1}{|c|}{ O } & \multicolumn{1}{|c|}{ T } \\
\hline Coughing & Tosse \\
\hline Choking when you eat food & Engasgo quando me alimento \\
\hline Having thick saliva or phlegm & Apresento saliva grossa ou secreção \\
\hline
\end{tabular}

Fonte: Elaborado pelo autor.

Tabela 16 - Itens de resposta da questão 3

Notamos que o os itens da questão 3 começam com o uso de um substantivo, "tosse", e depois mudam para verbo, "engasgo" e "apresento", ou 
seja, ocorre erro de padronização por não haver continuidade no padrão dos itens de resposta dessa questão. Uma vez que a questão solicita ao paciente que ele informe com que frequência as situações listadas ocorrem no seu dia a dia, o mais apropriado seria que os itens fossem escritos utilizando substantivos. Sugerimos, então, que os itens sejam apresentados da seguinte forma:

\begin{tabular}{|l|}
\hline \multicolumn{1}{|c|}{ S } \\
\hline Tosse \\
\hline Engasgo durante a alimentação \\
\hline Saliva grossa ou secreção \\
\hline
\end{tabular}

Fonte: Elaborado pelo autor.

Tabela 17 - Sugestão

Dessa maneira, utilizamos o recurso denominado paralelismo sintático e semântico, neste caso em específico de ordem morfológica, pois todos os itens passam a serem iniciados com substantivo, ou seja, com a mesma classe gramatical (Duarte [2012?]).

Já nos itens de resposta da questão 9, houve a utilização do recurso de paralelismo, mas há inadequação quanto ao uso do tempo verbal uma vez que a questão se refere aos acontecimentos do último mês, "in the last month", e os itens de resposta são apresentados no presente: 


\begin{tabular}{|l|l|}
\hline \multicolumn{1}{|c|}{ O } & \multicolumn{1}{c|}{ T } \\
\hline Feel weak? & Sente-se fraco? \\
\hline Feel tired? & Sente-se cansado? \\
\hline Feel exhausted? & Sente-se exausto? \\
\hline
\end{tabular}

Fonte: Elaborado pelo autor.

Tabela 18 - Itens de resposta questão 9

Sugerimos então, os itens de resposta desta forma:

\begin{tabular}{|l|}
\hline \multicolumn{1}{|c|}{ S } \\
\hline Feel weak? \\
Sentiu-se fraco? \\
\hline $\begin{array}{l}\text { Feel tired? } \\
\text { Sentiu-se cansado? }\end{array}$ \\
\hline $\begin{array}{l}\text { Feel exhausted? } \\
\text { Sentiu-se exausto? }\end{array}$ \\
\hline
\end{tabular}

Fonte: Elaborado pelo autor.

Tabela 19 - Sugestão

É interessante lembrar que, no original, a questão 9 era composta por cinco itens de resposta, dois dos quais se referiam ao sono e três se referiam à fadiga. Já na tradução, a questão 9 foi dividida em duas questões, a 9 e a 10. A questão 9 passou a contemplar os itens de resposta referentes ao sono, como vemos nesse trecho da análise, e a questão 10 passou a contemplar os itens de resposta referentes à fadiga. 


\section{Considerações finais}

A análise comparativa entre as versões original e traduzida do questionário de avaliação de qualidade de vida em disfagia, o SWAL-QOL, possibilitou demonstrar a relevância da participação do profissional tradutor em processos tradutórios envolvendo instrumentos de avaliação na área da saúde.

Foram encontradas inadequações nos níveis estrutural e linguístico. No nível estrutural, observamos a omissão, por exemplo, do quadro inicial que deveria demonstrar para o paciente como o questionário deve ser preenchido, além da omissão de recursos como negrito e itálico que também facilitam a compreensão do paciente. No nível linguístico, observamos omissões desnecessárias de termos, falta de paralelismo, escolhas inadequadas de termos.

Por meio do levantamento dessas inadequações e das sugestões propostas, acreditamos ter contribuído com a teoria da tradução, alcançando o nosso objetivo de fornecer material de leitura para alunos de tradução e tradutores iniciantes na área da saúde, além de esclarecer a importância de se trabalhar com profissionais tradutores.

Ressaltamos ainda que diretrizes - como as propostas por Guillemin et al. (1993) e Beaton et al. (2000), as quais incluem orientações para se atingir uma equivalência semântica, idiomática, experiencial e conceitual entre o original e sua tradução - que foram utilizadas como base para nossa análise devem ser seguidas pelos tradutores que participarem de processos tradutórios na área da saúde.

\section{Referências}

AUBERT, F. H. Modalidades de tradução: teorias e resultados. Tradterm, São Paulo, v. 5, n. 1, p. 99-128, 1998. Disponível em: <http://www.revistas.usp.br/tradterm/article/view/49775/53879>. Acesso em 02 fev. 2015.

AZENHA JUNIOR, J. Tradução técnica e condicionantes culturais: primeiros passos para um estudo integrado. São Paulo: Humanitas, 1999.

BARBOSA, H. Procedimentos técnicos da tradução: uma nova proposta. 2. ed. Campinas: Pontes, 2004.

BEATON, D. et al. Guidelines for the process of cross-cultural adaptation of self-report measures. Spine, Hagerstown, v. 25, n. 24, p. 3186-3191, dez. 2000. 
CARMO, B. B. et al. Instrumentos de avaliação estrangeiros no contexto da saúde brasileira: processo de tradução, adaptação cultural e validação. Meta: Avaliação, Rio de Janeiro, v. 4, n. 11, p. 120-134, mai./ago. 2012.

DUARTE, V. M. do N. Paralelismo Sintático e Paralelismo Semântico: recursos que compõem o estilo textual. Português, [2012?]. Disponível em: $<$ http://www.portugues.com.br/redacao/paralelismo-sintatico-paralelismosemantico---recursos-que-compoem-estilo-textual--.html>. Acesso em: 15 maio 2015.

GUILLEMIN, F. et al. Cross Cultural adaptation of health-related quality of life measures: literature review and proposed guidelines. J Clin Epidemiol, Oxford, v. 46, n. 12, p. 1417-1432, dez. 1993.

MCHORNEY, C. A. et al. The SWAL-QOL outcomes tool for oropharyngeal dysphagia in adults: I. conceptual foundation and item development. Dysphagia, New York, v. 15, n. 3, p. 115-121, 2000.

The SWAL-QOL and SWAL-CARE outcomes tool for oropharyngeal dysphagia in adults: III. documentation of reliability and validity. Dysphagia, New York, v. 17, n. 2, p. 97-114, 2002.

MONTONI, N. P.; ALVES, I. S. Tradução e adaptação transcultural dos questionários SWAL-QOL e SWAL-CARE versão português-Brasil. 2006. Monografia (Conclusão do Curso de Pós-Graduação Lato Sensu "Motricidade Oral") - Fundação Antônio Prudente, São Paulo, 2006.

NORD, C. Text analysis in translation: theory, methodology, and didactic application of a model for translation-oriented text analysis. 2. ed. Amsterdam/Nova York, NY: Rodopi, 2005.

NORMAS para apresentação de teses e dissertações. Puc-Rio, [2015?]. Disponível em: <https://www.puc-rio.br/ensinopesq/ccpg/normas/aspas_italico_negrito.html>. Acesso em: 10 maio 2015.

NOTA. In: DICIO - Dicionário online de português, c2009-2015. Disponível em: <http://www.dicio.com.br/nota/>. Acesso em: 21 maio 2015.

NOTE. In: LONGMAN Dictionary of Contemporary English, [2015?]. Disponível em: <http://www.ldoceonline.com/dictionary/note_2>. Acesso em: 21 maio 2015.

PAGANO, A. Crenças sobre a tradução e o tradutor: revisão e perspectivas para novos planos de ação. In: ALVES, F.; MAGALHÃES, C.; PAGANO, A. 
(Org.). Traduzir com Autonomia. Estratégicas para tradutor em formação. São Paulo: Contexto, 2000. p. 09.

PORTAS, J. G. Validação para a língua portuguesa-brasileira dos questionários: Qualidade de vida em disfagia (SWAL-QOL) e Satisfação do paciente e qualidade do cuidado no tratamento da disfagia (SWAL-CARE). 2009. 58 p. Dissertação (Mestrado em Ciências) - Fundação Antônio Prudente, São Paulo, 2009.

RÓNAI, P. Definições da Tradução e do Tradutor. In: . A Tradução Vivida. Rio de Janeiro: Nova Fronteira, 1981.

SINÔNIMOS de periodicidade. Sinônimos, c2011-2015. Disponível em: <http://www.sinonimos.com.br/periodicidade/>. Acesso em: 02 jun 2015.

Resumo: Este estudo buscou demonstrar a relevância da participação do tradutor em processos tradutórios na área da saúde. Para isso, realizamos uma análise comparativa entre as versões original e traduzida de um questionário de avaliação de qualidade de vida em disfagia, o SWAL-QOL, com base em diretrizes para a tradução na área da saúde propostas por Beaton et al. (2000), além de conceitos da teoria da tradução. As inadequações encontradas nos níveis estrutural e linguístico possibilitaram demonstrar a relevância da participação do tradutor em processos tradutórios na área da saúde.

Palavras-chave: tradução científica, qualidade de vida, disfagia

\begin{abstract}
This study aimed to show the relevance of the participation of the translator in translation procedures in the health area. We carried out a comparative analysis between the original and the translation of an evaluation questionnaire of quality of life in dysphagia, SWAL-QOL, based on the guidelines for translation in the health area by Beaton et al. (2000), besides some translation theory. The problems found in the structural and linguistic levels enabled us to demonstrate the relevance of the participation of the translator in translation processes in this area.
\end{abstract}

Keywords: scientific translation, quality of life, dysphagia 